\title{
Característica histológica, ultra-estrutural e produção de nitrito de folículos pré-antrais caprinos cultivados in vitro na ausência ou presença de soro
}

\author{
[Histological and ultrastructural feature and nitrite production of caprine preantral follicles in vitro \\ cultured in the presence or absence of serum]
}

\author{
J.B. Bruno ${ }^{1}$, I.B. Lima-Verde ${ }^{1}$, F.S. Martins ${ }^{1}$, M.H.T. Matos ${ }^{1}$, C.A.P. Lopes ${ }^{1}$, J.E. Maia-Jr. ${ }^{1}$, S.N. Báo ${ }^{2}$, \\ H.V. Nobre Junior ${ }^{3}$, F.D. Maia ${ }^{3}$, C. Pessoa ${ }^{3}$, M.O. Moraes ${ }^{3}$, \\ J.R.V. Silva ${ }^{1}$, J.R. Figueiredo ${ }^{1}$, A.P.R. Rodrigues ${ }^{1}$ \\ ${ }^{1}$ Faculdade de Medicina Veterinária - UECE \\ Av. Paranjana, 1700 \\ 60740-000 - Fortaleza, CE \\ ${ }^{2}$ Instituto de Ciências Biológicas - UnB - Brasília, DF \\ ${ }^{3}$ Universidade Federal do Ceará - Fortaleza, CE
}

\begin{abstract}
RESUMO
Avaliou-se o efeito da adição de diferentes tipos e concentrações de soro sobre o desenvolvimento e a sobrevivência de folículos ovarianos pré-antrais (FOPA) caprinos in vitro. Além disso, verificou-se a relação entre as concentrações de nitrito presentes no meio de cultivo e a viabilidade folicular. Cada par ovariano foi dividido em 29 fragmentos, sendo um destinado ao controle. Os fragmentos foram cultivados por um ou sete dias em meio essencial mínimo suplementado $\left(\mathrm{MEM}^{+}\right)$ou $\mathrm{MEM}^{+}$com diferentes concentrações (10 ou 20\%) de soro fetal bovino (SFB), soro de cabra em estro (SCE) ou soro de cabra em diestro (SCD). Na análise morfológica após sete dias, apenas o tratamento com 10\% de SFB apresentou percentual de FOPA normais similar ao $\mathrm{MEM}^{+}(\mathrm{P}>0,05)$. A análise ultra-estrutural dos folículos cultivados por sete dias com $\mathrm{MEM}^{+}$ou $\mathrm{MEM}^{+}$com $10 \%$ de SFB mostrou danos oocitários, porém células da granulosa normais. A análise do meio de cultivo revelou correlação positiva entre a viabilidade folicular e a produção de nitrito. A suplementação com soro não melhorou a viabilidade de FOPA e a concentração de nitrito no meio de cultivo funcionou como um indicador da viabilidade das células da granulosa de FOPA caprinos cultivados in vitro.
\end{abstract}

Palavras-chave: caprino, folículo pré-antral, cultivo in vitro, soro

\begin{abstract}
The effect of the addition of different types and concentrations of sera on the viability and development of caprine preantal follicles $(P A F)$ in vitro cultured was analyzed. In addition, it was evaluated the correlation between nitrite concentrations in culture medium and folicular viability. Each ovarian pair was divided in 29 fragments and one was used as control. The fragments were cultured for one or seven days in minimal essential medium $\left(M E M^{+}\right)$or $M E M^{+}$with different concentrations of (10 or 20\%) bovine fetal serum (BFS), estrous goat serum (EGS), or diestrous goat serum (DGS). After seven days, the morphological analysis showed that only the treatment with $10 \%$ BFS maintained the percentage of normal PAF similar to MEM $M^{+}(P>0.05)$. The ultrastructural analysis of follicles cultured for seven days in $M E M^{+}$or $M E M^{+}$with $10 \%$ BFS showed some oocyte damage, although the granulosa cells were normal. Analysis of culture medium revealed a positive correlation between follicular viability and nitrite production. Supplementation with serum did not improve the viability of PAF and nitrite levels in culture medium served as an indicator of viability of granulose cells from caprine $P A F$ in vitro cultured.
\end{abstract}

Keywords: caprine, preantral follicle, in vitro culture, serum

Recebido em 22 de fevereiro de 2008

Aceito em 2 de novembro de 2008

E-mail: jamily_vet@yahoo.com.br 


\section{INTRODUÇÃO}

No ovário mamífero, a morfologia folicular normal modifica-se, uma vez que o oócito cresce e suas células circundantes se diferenciam, mantendo a funcionalidade do órgão para garantir sua capacidade fecundante. Paralelamente a esse processo, os folículos podem tornar-se atrésicos, levando a uma perda folicular de $99,9 \%$ ao longo da vida reprodutiva do animal (Mao et al., 2002). As altas taxas de atresia reduzem consideravelmente o potencial reprodutivo da fêmea mamífera. Portanto, estudos in vitro que possibilitam conhecer as substâncias e fatores envolvidos na viabilidade, ativação, crescimento e morte folicular podem contribuir para a maximização do potencial reprodutivo.

Vários sistemas de cultivo in vitro de folículos ovarianos pré-antrais (FOPA) têm sido sugeridos por diferentes pesquisadores, porém os resultados em relação à viabilidade e ao desenvolvimento folicular são variáveis, dependendo do meio de cultivo utilizado (Matos et al., 2007). Muitos trabalhos têm sugerido a adição de soro, como fonte de nutrientes, hormônios e fatores de crescimento, ao meio de cultivo de FOPA, sendo os resultados dessa adição controversos. Alguns autores verificaram que o soro promove efeitos benéficos durante o cultivo in vitro de FOPA (humanos: Wright et al., 1999; bovinos: Saha et al., 2000; suínos: Telfer et al., 2000), porém outros observaram que o soro é prejudicial tanto durante o cultivo in vitro de FOPA (Thomas et al., 2001) como de embriões bovinos (Mucci et al., 2006). A maioria dos estudos aponta a adição de soro fetal bovino na concentração de $10 \%$ durante o cultivo in vitro de FOPA (Cecconi et al., 1999; Zhou e Zhang, 2005), porém outros tipos e concentrações de soro também são utilizados (Wright et al., 1999; Mao et al., 2002). Entretanto, não se tem relato do efeito de diferentes origens e concentrações de soro sobre a viabilidade e o desenvolvimento de FOPA caprinos cultivados in vitro.

A avaliação da viabilidade e do desenvolvimento folicular in vitro tem sido mostrada principalmente por meio da análise histológica e ultra-estrutural. Porém, outra ferramenta que também pode vir a ser utilizada é a detecção, no meio de cultivo, das concentrações de nitrito, um dos produtos do metabolismo oxidativo do óxido nítrico (NO). O NO é um mensageiro intracelular de produção endógena que previne a apoptose em vários tipos celulares, tais como células endoteliais (Dimmeler et al., 1997) e folículos ovarianos (Chun et al.,
1995), podendo ser utilizado como marcador de normalidade dessas estruturas. Até o presente não foram mensuradas as concentrações de nitrito no meio de cultivo de FOPA, nem feita uma correlação entre sua produção e a viabilidade folicular. Assim, o objetivo deste trabalho foi avaliar o efeito da adição de diferentes tipos e concentrações de soro no cultivo in vitro de FOPA de caprinos sobre o desenvolvimento e a viabilidade folicular, bem como a correlação desta com a concentração de nitrito no meio de cultivo.

\section{MATERIAL E MÉTODOS}

Foram utilizados oito ovários de quatro cabras adultas, sem raça definida, provenientes de abatedouros locais. Imediatamente após o abate, os ovários foram lavados em álcool $70 \%$ e em solução salina $0,9 \%$. O par ovariano de cada animal foi transportado, dentro de aproximadamente $1 \mathrm{~h}$, ao laboratório, em solução salina $0,9 \%$, à temperatura de aproximadamente $33^{\circ} \mathrm{C}$.

Utilizou-se meio essencial mínimo (MEM) ${ }^{1}$ suplementado com $1,0 \mathrm{~g} / 1$ de insulina, $0,55 \mathrm{~g} / 1 \mathrm{de}$ transferrina e $0,67 \mathrm{mg} / 1$ de selênio (ITS) ${ }^{2}, 100 \mu \mathrm{g} / \mathrm{ml}$ de penicilina $^{3}$ e estreptomicina ${ }^{3}, 0,25 \mu \mathrm{g} / \mathrm{ml}$ de anfotericina $\mathrm{B}^{4}, 0,23 \mathrm{mM}$ de piruvato ${ }^{4}, 2 \mathrm{mM}$ de glutamina $^{4}$ e $2 \mathrm{mM}$ de hipoxantina ${ }^{4}$. O MEM adicionado desses suplementos e sem adição de soro foi denominado de $\mathrm{MEM}^{+}$.

Para o cultivo in vitro, foram utilizados soro de cabra em estro (SCE) e soro de cabra em diestro (SCD), obtidos de sangue retirado da veia jugular de animais no primeiro e $10^{\circ}$ dias do ciclo estral, respectivamente e, ainda, soro fetal bovino $(\mathrm{SFB})^{5}$.

O sangue coletado foi imediatamente centrifugado a 9560xg durante $15 \mathrm{~min}$ e filtrado em filtros de $0,22 \mu \mathrm{m}$. Em seguida, foi inativado em banho-maria a $56^{\circ} \mathrm{C}$ por $30 \mathrm{~min}$, dividido em alíquotas de $1 \mathrm{ml} \mathrm{e}$ estocado $\mathrm{a}-20^{\circ} \mathrm{C}$ até o momento de sua utilização.

No laboratório, foram retirados os tecidos circundantes e ligamentos de cada par ovariano. Posteriormente, cada ovário foi cortado ao meio, e a medula, os folículos antrais e os corpos lúteos, quando presentes, foram removidos. De cada par ovariano, foi retirado um fragmento de $9 \mathrm{~mm}^{3}$ e outro de $1 \mathrm{~mm}^{3}$ para análise histológica e ultra-

\footnotetext{
${ }^{1}$ Cultilab - Rio de Janeiro, Brasil.

${ }^{2}$ Gibco - New York, EUA

${ }^{3}$ Vetec - Rio de Janeiro, Brasil.

${ }^{4}$ Sigma Chemical Co - St. Louis, EUA.

${ }^{5}$ Nutricell - Campinas, Brasil.
} 
estrutural, respectivamente, os quais foram imediatamente fixados em $10 \%$ de formol por $12 \mathrm{~h}$, constituindo o controle (fragmentos frescos ou não cultivados). Em seguida, o córtex de cada par ovariano foi dividido em 28 fragmentos de aproximadamente $9 \mathrm{~mm}^{3}$, sendo dois fragmentos por tratamento, e distribuídos aleatoriamente em diferentes meios de cultivo na ausência ou presença de diferentes origens e concentrações de soro, correspondendo aos seguintes tratamentos: $\mathrm{MEM}^{+}$só ou: suplementado com $10 \%$ de soro fetal bovino (SFB 10), ou com $20 \%$ de soro fetal bovino (SFB 20), ou com $10 \%$ de soro de cabra em estro (SCE 10), ou com $20 \%$ de soro de cabra em estro (SCE 20), ou com 10\% de soro de cabra em diestro (SCD 10) ou com 20\% de soro de cabra em diestro (SCD 20). Cada fragmento ovariano foi cultivado individualmente por um ou sete dias em placas de 24 poços, contendo $1 \mathrm{ml}$ de meio de cultivo por poço. O cultivo folicular foi realizado em estufa calibrada a $39^{\circ} \mathrm{C}$ na presença de ar a $5 \%$ de $\mathrm{CO}_{2}$. A cada dois dias, o meio de cultivo foi substituído por meio fresco.

Para avaliar a morfologia dos FOPA, os fragmentos de tecido ovariano não cultivados, bem como aqueles cultivados por um ou sete dias foram fixados em $10 \%$ de formol por $12 \mathrm{~h}$. Após a fixação, os fragmentos ovarianos foram desidratados, diafanizados, incluídos em blocos de parafina (Matos et al., 2007) e seccionados seriadamente à espessura de $7 \mu \mathrm{m}$. Cada quinta secção foi montada em lâmina e corada pelo método do ácido periódico de Schiff (PAS)hematoxilina ${ }^{4}$. Todas as secções foram examinadas utilizando um microscópio ótico ${ }^{6}$.

Foram avaliados 30 FOPA por tratamento, em cada período de cultivo e em cada repetição. Segundo o estádio de desenvolvimento folicular, os FOPA foram classificados como primordiais (oócito circundado por células da pré-granulosa de forma pavimentosa) e em desenvolvimento (oócito circundado por uma camada de células da pré-granulosa de forma pavimentosa e pelo menos uma célula da granulosa de formato cúbico). A qualidade folicular foi avaliada baseada em parâmetros morfológicos como a integridade do oócito e das células da granulosa. Os FOPA foram classificados ainda como morfologicamente normais (folículos contendo

\footnotetext{
${ }^{6}$ Zeiss - Germany.
}

oócito e células da granulosa intactos) ou folículos degenerados (folículos apresentando oócito com núcleo picnótico ou retração oocitária, acompanhados ou não por destacamento das células da granulosa da membrana basal). A proporção de folículos primordiais e em desenvolvimento foi calculada no dia zero (controle) e após um e sete dias de cultivo, nos diferentes tratamentos testados. O diâmetro folicular foi mensurado com auxílio de uma ocular micrométrica ${ }^{7}$.

Após um e sete dias, $100 \mu 1$ de meio de cultivo oriundo de cada tratamento foram coletados e armazenados em placas de 96 poços a $-20^{\circ} \mathrm{C}$ para posterior mensuração da concentração de nitrito, determinada segundo o método de Green et al. (1981), que se baseia em revelar a presença de nitrito em uma amostra (urina, plasma, homogenato tecidual e sobrenadante celular) por uma reação de diazotização que forma um cromóforo róseo, com pico de absorbância de $560 \mathrm{~nm}$. Para esse ensaio, $100 \mu \mathrm{l}$ do reativo de Griess (sulfanilamida a 1\%, cloridrato de N-(1naftil)-etilenediamina $0,1 \%, \mathrm{H}_{3} \mathrm{PO}_{4}$ em $1 \%$, água destilada, na proporção de $1: 1: 1: 1)$ foi adicionado a $100 \mu$ l do meio de cultivo e incubado à temperatura ambiente por $10 \mathrm{~min}$. A curva padrão foi elaborada com várias concentrações de $\mathrm{NaNO}_{2}$ (variando de 0,75 a $100 \mu \mathrm{M})$ sob as mesmas condições. Os brancos (controle negativo) foram preparados pela adição de $100 \mu l$ do reativo de Griess a $100 \mu l$ do meio de base a uma absorbância de $560 \mathrm{~nm}$ em um leitor de microplacas ${ }^{8}$.

A análise ultra-estrutural, por meio de microscopia eletrônica de transmissão (MET), foi realizada em FOPA oriundos do controle e naqueles considerados morfologicamente normais, provenientes dos diferentes tratamentos testados. Para isso, os fragmentos de tecido ovariano foram fixados em solução contendo $2 \%$ de paraformaldeído ${ }^{9}$ e $2,5 \%$ de glutaraldeído ${ }^{9}$ em tampão cacodilato de sódio $^{9}(\mathrm{pH} 7,2)$. Após a fixação, os fragmentos foram pós-fixados em $1 \%$ de tetróxido de ósmio ${ }^{9}, 0,8 \%$ de ferricianeto de potássio ${ }^{9}$ e $5 \mathrm{mM}$ de $\mathrm{CaCl}_{2}{ }^{9}$ em tampão cacodilato de sódio ${ }^{9}$. Em seguida, as amostras

\footnotetext{
${ }^{7}$ Nikon - Japan.

${ }^{8}$ Metertech Inc. - Taipei, Taiwan.

${ }^{9}$ Electron Microscopy Sciences - Washington, EUA.
} 
foram desidratadas em acetona ${ }^{10}$ e embebidas em resina Spurr'. Os cortes ultra-finos $(80 \mathrm{~nm})$ foram preparados quando o núcleo do oócito foi observado no corte semi-fino $(3 \mu \mathrm{m})$. Os cortes semi-finos foram corados com azul de toluidina enquanto os cortes ultra-finos foram contrastados com acetato de uranila e citrato de chumbo e examinados em microscópio eletrônico de transmissão ${ }^{11}$. Na avaliação ultra-estrutural foram observados os seguintes parâmetros: integridade das organelas citoplasmáticas do oócito e das células da granulosa, grau de vacuolização citoplasmática e integridade da membrana basal.

A análise estatística foi realizada com base nos princípios descritos por Steel et al. (1997). As percentagens de folículos normais, primordiais e em desenvolvimento no controle e após cada período de cultivo nos vários tratamentos foram submetidas a transformação angular (arco-seno) e posterior análise de variância (ANAVA), sendo as médias comparadas pelo teste PLSD de Fisher. Os diâmetros foliculares no tecido não cultivado e cultivado não apresentaram homocedasticidade e foram analisados pelo teste não paramétrico Kruskal-Wallis. Os dados referentes à produção de nitrito nos diferentes tratamentos foram submetidos à ANAVA e as médias comparadas pelo teste Tukey. Os resultados foram expressos como média $\pm E P$, sendo os valores considerados significativamente diferentes quando $\mathrm{P}<0,05$.

\section{RESULTADOS}

Os FOPA caprinos presentes no tecido ovariano foram considerados morfologicamente normais quando o oócito apresentava-se esférico ou ligeiramente alongado, com núcleo sem evidência de picnose e células da granulosa bem organizadas circundando o oócito. Os FOPA degenerados apresentavam-se com retração citoplasmática, núcleo do oócito picnótico ou células da granulosa desorganizadas em torno do oócito (Fig. 1).

Foram analisados 120 folículos por tratamento perfazendo um total de 1.800 folículos. A Fig. 2 mostra o percentual de FOPA morfologicamente normais no controle, bem como após cultivo in vitro por um ou sete dias. Em todos os tratamentos após um ou sete dias de cultivo in vitro, foi verificada redução significativa $(\mathrm{P}<0,05)$ nos percentuais de FOPA normais em relação ao

\footnotetext{
${ }^{10}$ Sigma, Inc. - St. Louis, MO, EUA.
}

${ }^{11}$ Jeol JEM- 1011 - Tóquio, Japão. controle, exceto quando se utilizou $\mathrm{MEM}^{+}$sozinho ou com a adição de 10 ou $20 \%$ de SFB por um dia. Quando comparado ao $\mathrm{MEM}^{+}$, foi verificada redução significativa $(\mathrm{P}<0,05)$ em todos os tratamentos, exceto após um dia de cultivo quando o $\mathrm{MEM}^{+}$foi suplementado com 10 ou $20 \%$ de SFB ou $10 \%$ SCE e, após sete dias, quando foram adicionados $10 \%$ de SFB. O aumento da concentração de 10 para $20 \%$ do SCE e do SFB, após um ou sete dias, respectivamente, levou à redução significativa $(\mathrm{P}<0,05)$ no percentual de FOPA morfologicamente normais.

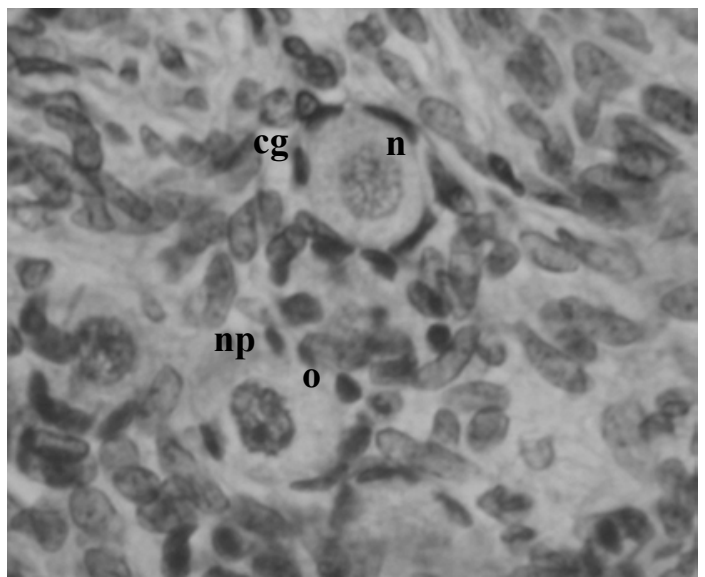

Figura 1. Secção histológica de tecido ovariano caprino cultivado por sete dias em $10 \%$ de soro fetal bovino mostrando um folículo normal e um degenerado. Notar a intensa picnose nuclear no folículo degenerado. n: núcleo do oócito normal, np: núcleo do oócito picnótico, o: oócito, cg: células da granulosa (400X).

$\mathrm{Na}$ Tab. 1 mostra-se a percentagem de folículos primordiais e em desenvolvimento no tecido cortical ovariano antes e após um e sete dias de cultivo. Em todos os tratamentos testados, inclusive quando foram utilizados $10 \%$ de SFB, após um e sete dias de cultivo, observaram-se redução e aumento significativos no percentual de folículos primordiais e em desenvolvimento, respectivamente, quando comparado ao controle (não-cultivado) $(\mathrm{P}<0,05)$, exceto no tratamento $\mathrm{MEM}^{+}$após um dia de cultivo $(\mathrm{P}>0,05)$. Quando comparado ao $\mathrm{MEM}^{+}$, após um dia de cultivo, o tecido cortical cultivado com $20 \%$ de SCE mostrou, simultaneamente, redução e aumento significativos na percentagem de folículos primordiais e em desenvolvimento, respectivamente $(\mathrm{P}<0,05)$. Entretanto, após sete dias, esses tratamentos foram similares $(\mathrm{P}>0,05)$. 


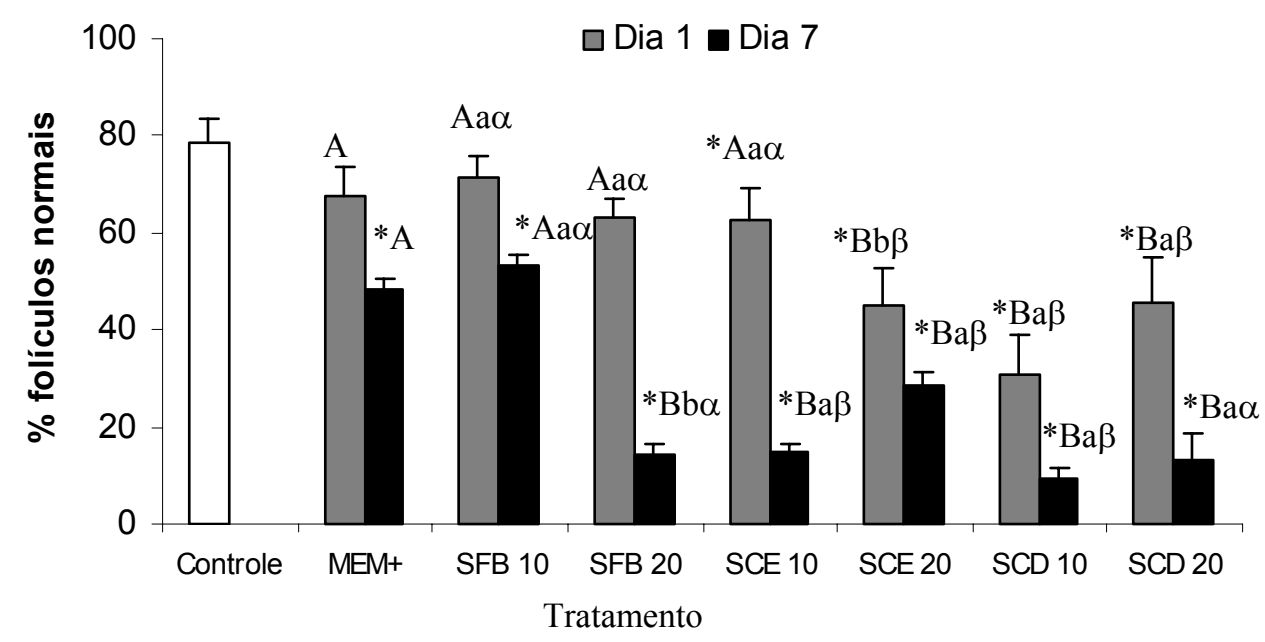

Figura 2. Percentagem (média \pm EP) de folículos pré-antrais caprinos morfologicamente normais no controle (não cultivado) e após cultivo in vitro por um ou sete dias na ausência ou presença de soro. $\mathrm{MEM}^{+}$: meio essencial mínimo suplementado; SFB: soro fetal bovino; SCE: soro de cabra em estro; SCD: soro de cabra em diestro.

*Diferem estatisticamente do controle $(\mathrm{P}<0,05)$. Letras maiúsculas distintas indicam diferença do $\mathrm{MEM}^{+}$ dentro de cada dia de cultivo $(\mathrm{P}<0,05)$; letras minúsculas distintas indicam diferença entre a mesma substância em diferentes concentrações $(\mathrm{P}<0,05)$; letras gregas distintas indicam diferença entre substâncias diferentes na mesma concentração $(\mathrm{P}<0,05)$.

Tabela 1. Percentagem (média \pm EP) de folículos caprinos primordiais e em desenvolvimento no controle (não-cultivado) e após cultivo in vitro por um ou sete dias na ausência ou presença de soro

\begin{tabular}{|c|c|c|c|c|}
\hline & \multicolumn{2}{|c|}{ Folículo primordial } & \multicolumn{2}{|c|}{ Folículos em desenvolvimento } \\
\hline Controle & \multicolumn{2}{|c|}{$76,4 \pm 7,4$} & \multicolumn{2}{|c|}{$23,6 \pm 7,4$} \\
\hline Tratamento & Dia 1 & Dia 7 & Dia 1 & Dia 7 \\
\hline $\mathrm{MEM}^{+}$ & $51,2 \pm 11,5 \mathrm{~A}$ & $15,9 \pm 7,5^{*} \mathrm{~A}$ & $48,8 \pm 11,5 \mathrm{~A}$ & $84,1 \pm 7,5 * \mathrm{~A}$ \\
\hline SFB 10 & $16,7 \pm 2,8 * \mathrm{Ba} \alpha$ & $6,5 \pm 2,7 * \mathrm{Aa} \alpha$ & $83,3 \pm 2,8 * \mathrm{Aa} \alpha$ & $93,5 \pm 2,7 * \mathrm{Aa} \alpha$ \\
\hline SFB 20 & $25,3 \pm 10,8 * \mathrm{Aa} \alpha$ & $25,8 \pm 4,3 * \mathrm{Aa} \alpha$ & $74,7 \pm 10,8 * \mathrm{Aa} \alpha$ & $74,2 \pm 4,3 * \mathrm{Aa} \alpha$ \\
\hline SCE 10 & $27,2 \pm 8,8 * \mathrm{Aa} \alpha$ & $15,0 \pm 9,5 * \mathrm{Aa} \alpha$ & $72,8 \pm 8,8 * \mathrm{Aa} \alpha$ & $85,0 \pm 9,5 * \mathrm{Aa} \alpha$ \\
\hline SCE 20 & $10,9 \pm 3,9 * \mathrm{Ba} \alpha$ & $17,8 \pm 10,7 * \mathrm{Aa} \alpha$ & $89,1 \pm 3,9 * \mathrm{Ba} \alpha$ & $82,2 \pm 10,7 * \mathrm{Aa} \alpha$ \\
\hline SCD 10 & $33,2 \pm 9,7 * \mathrm{Aa} \alpha$ & $12,5 \pm 12,5 * \mathrm{Aa} \alpha$ & $66,8 \pm 9,7 * \mathrm{Aa} \alpha$ & $87,5 \pm 12,5^{*} \mathrm{Aa} \alpha$ \\
\hline SCD 20 & $34,1 \pm 9,0 *$ Aa $\alpha$ & $7,7 \pm 4,4 * \mathrm{Aa} \alpha$ & $65,9 \pm 9,0 * \mathrm{Aa} \alpha$ & $67,3 \pm 22,7 * \mathrm{Aa} \alpha$ \\
\hline
\end{tabular}

*Diferem estatisticamente do controle $(\mathrm{P}<0,05)$. Letras maiúsculas distintas indicam diferença do $\mathrm{MEM}^{+}$dentro de cada dia de cultivo $(\mathrm{P}<0,05)$; letras minúsculas distintas indicam diferença entre a mesma substância em diferentes concentrações $(\mathrm{P}<0,05)$; letras gregas distintas indicam diferença entre substâncias diferentes na mesma concentração $(\mathrm{P}<0,05)$.

$\mathrm{MEM}^{+}$: meio essencial mínimo suplementado; SFB: soro fetal bovino; SCE: soro de cabra em estro; SCD: soro de cabra em diestro. 
Quanto ao crescimento, a Tab. 2 mostra o diâmetro folicular no tecido ovariano fresco e cultivado por um ou sete dias. Foi observado que apenas os FOPA cultivados em meio com $20 \%$ de SCE por sete dias apresentaram diâmetro folicular maior que o controle $(\mathrm{P}<0,05)$, porém semelhante ao cultivo com $\mathrm{MEM}^{+}(\mathrm{P}>0,05)$.

Tabela 2. Diâmetro folicular (média $\pm E P$ ) no controle (não-cultivado) e após cultivo in vitro de folículos caprinos por um ou sete dias na ausência ou presença de soro

\begin{tabular}{lcc}
\hline & \multicolumn{2}{c}{ Diâmetro folicular $(\mu \mathrm{m})$} \\
\hline Controle & \multicolumn{2}{c}{$57,1 \pm 1,8$} \\
\hline Tratamento & Dia 1 & Dia 7 \\
\hline MEM $^{+}$ & $58,55 \pm 2,0 \mathrm{~A}$ & $61,4 \pm 2,5 \mathrm{~A}$ \\
SFB 10 & $52,0 \pm 2,1 \mathrm{Ba} \alpha$ & $57,7 \pm 2,0 \mathrm{Aa} \alpha \beta$ \\
SFB 20 & $51,4 \pm 1,7 \mathrm{Ba} \alpha \beta$ & $50,6 \pm 2,0 * \mathrm{Bb} \alpha$ \\
SCE 10 & $60,5 \pm 1,9 \mathrm{Aa} \beta$ & $59,4 \pm 2,2 \mathrm{Aa} \alpha$ \\
SCE 20 & $57,7 \pm 2,8 \mathrm{Aa} \beta$ & $64,8 \pm 3,3 * \mathrm{Aa} \beta$ \\
SCD 10 & $53,7 \pm 2,0 \mathrm{Aa} \alpha$ & $52,9 \pm 2,3 \mathrm{Ba} \beta$ \\
SCD 20 & $50,2 \pm 2,3 * \mathrm{Ba} \alpha$ & $58,0 \pm 2,5 \mathrm{Aa} \gamma$
\end{tabular}

*Diferem estatisticamente do controle $(\mathrm{P}<0,05)$. Letras maiúsculas distintas indicam diferença do $\mathrm{MEM}^{+}$dentro de cada dia de cultivo $(\mathrm{P}<0,05)$; letras minúsculas distintas indicam diferença entre a mesma substância em diferentes concentrações $(\mathrm{P}<0,05)$; letras gregas distintas indicam diferença entre substâncias diferentes na mesma concentração $(\mathrm{P}<0,05)$.

$\mathrm{MEM}^{+}$: meio essencial mínimo suplementado; SFB: soro fetal bovino; SCE: soro de cabra em estro; SCD: soro de cabra em diestro.

Na Fig. 3 mostra-se a produção de nitrito após cultivo in vitro de FOPA por um ou sete dias na ausência ou presença de soro. Após um dia de cultivo, a concentração de nitrito no tratamento $\mathrm{MEM}^{+}$foi maior em relação aos demais tratamentos $(\mathrm{P}<0,05)$, exceto quando foram utilizados $10 \%$ de SFB ou SCE, os quais mostraram resultados similares ao $\mathrm{MEM}^{+}$ $(\mathrm{P}>0,05)$. Após sete dias de cultivo, todos os tratamentos apresentaram concentrações de nitrito significativamente inferiores ao tratamento $\mathrm{MEM}^{+} \quad(\mathrm{P}<0,05)$. Quando foram comparados os meios contendo soro após sete dias de cultivo, o tratamento com $10 \%$ de SFB apresentou concentração de nitrito mais elevada que os outros dois tipos de soro (SCE e SCD) nessa mesma concentração $(\mathrm{P}<0,05)$. Além disso, foi verificada correlação positiva após um $(\mathrm{R}=0,86 ; \mathrm{P}<0,05)$ e sete dias $(\mathrm{R}=0,76 ; \mathrm{P}<0,05)$ de cultivo entre o percentual de viabilidade folicular e a produção de nitrito.

A análise ultra-estrutural foi realizada somente em FOPA do controle e nos tratamentos $\mathrm{MEM}^{+}$ ou $\mathrm{MEM}^{+}$com $10 \%$ de SFB e $20 \%$ de SCE, os quais mostraram os melhores resultados de acordo com a análise histológica realizada previamente. Os achados ultra-estruturais mostraram que apenas os folículos do controle tiveram estruturas normais nos dois compartimentos (oócito e células da granulosa), apresentando núcleo do oócito bem delimitado, membrana nuclear e basal intactas, presença de alguns vacúolos e organelas bem distribuídas no citoplasma (Fig. 4A). Nos tratamentos $\mathrm{MEM}^{+}$ou $\mathrm{MEM}^{+}$com $10 \%$ de SFB após sete dias, os folículos apresentaram condensação da cromatina do oócito, aumento da vacuolização citoplasmática e danos na membrana nuclear e basal, porém as células da granulosa apresentaram-se ultra-estruturalmente normais (Fig. 4B). No entanto, os folículos cultivados na presença de $20 \%$ de SCE, mesmo durante a análise das secções semifinas, mostraram-se completamente degenerados com picnose oocitária e nas células da granulosa, aumento da vacuolização citoplasmática e destacamento das células da granulosa. 


\section{Característica histológica, ultra-estrutural...}

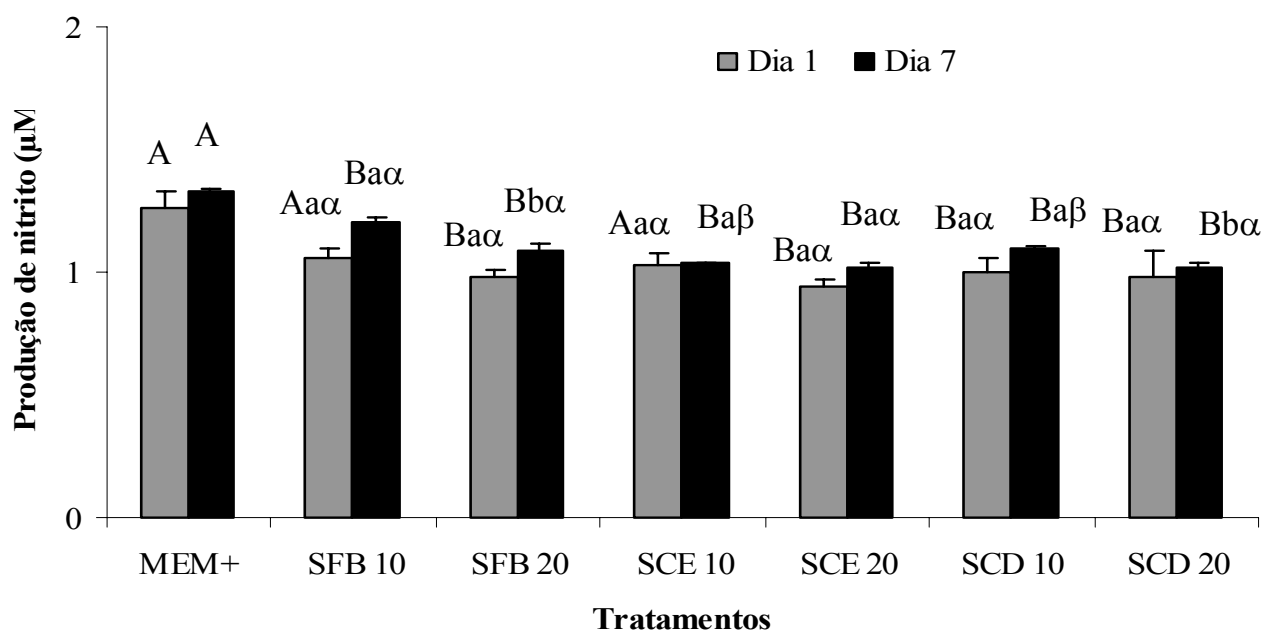

Figura 3. Concentração de nitrito (média \pm EP) no meio de cultivo de folículos pré-antrais caprinos por um ou sete dias na ausência ou presença de soro.

*Diferem estatisticamente do controle $(\mathrm{P}<0,05)$. Letras maiúsculas distintas indicam diferença do $\mathrm{MEM}^{+}$ dentro de cada dia de cultivo $(\mathrm{P}<0,05)$; letras minúsculas distintas indicam diferença entre a mesma substância em diferentes concentrações $(\mathrm{P}<0,05)$; letras gregas distintas indicam diferença entre substâncias diferentes na mesma concentração $(\mathrm{P}<0,05)$.

$\mathrm{MEM}^{+}$: meio essencial mínimo suplementado; SFB: soro fetal bovino; SCE: soro de cabra em estro; SCD: soro de cabra em diestro.
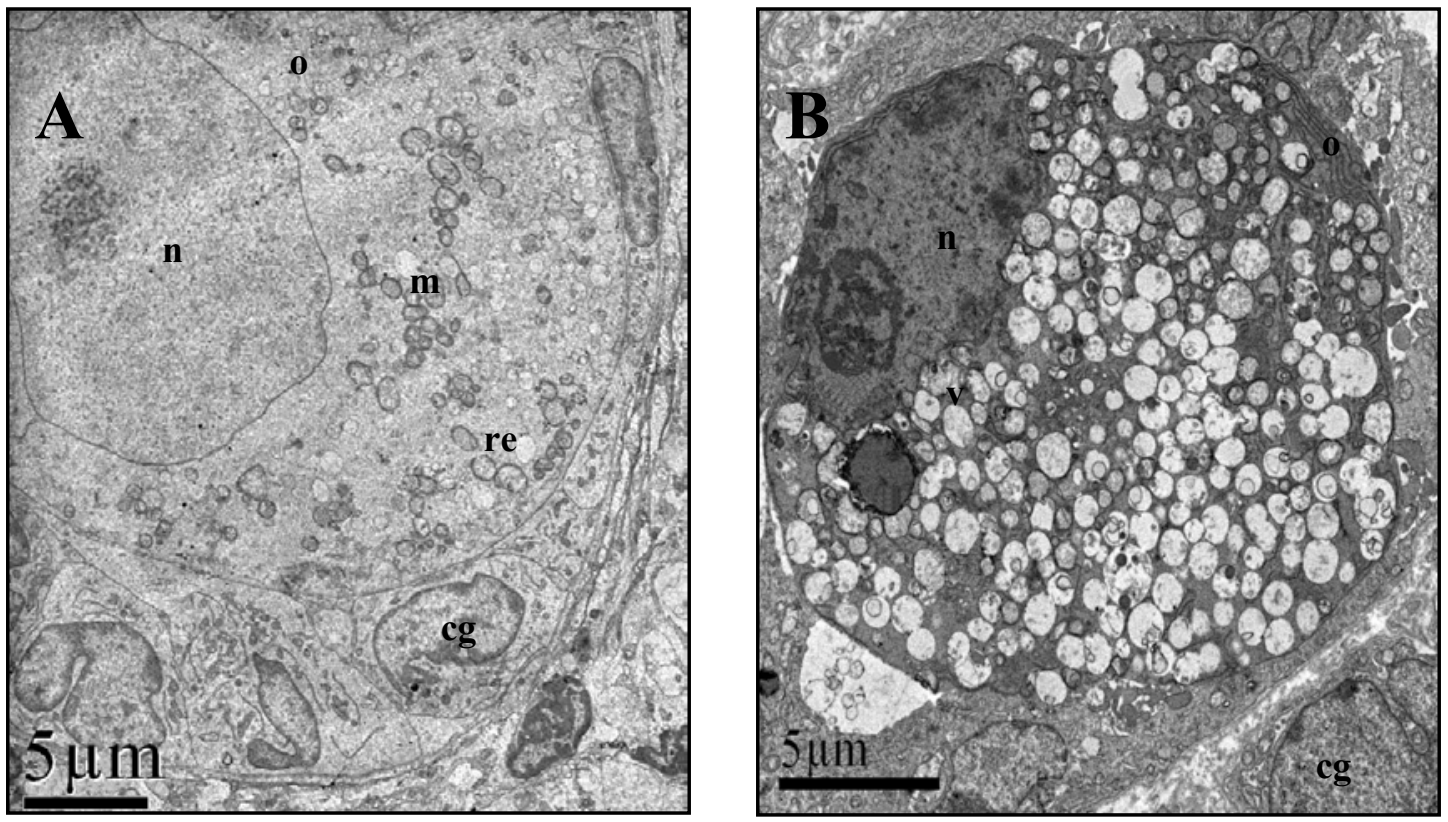

Figura 4. Fotomicrografia de um folículo caprino normal (A) (controle não-cultivado) (4000X) e degenerado (B) (cultivado por sete dias em meio essencial mínimo suplementado) (6000X). O citoplasma do folículo normal é homogêneo e possui numerosas mitocôndrias. Notar que o folículo cultivado apresenta extrema vacuolização citoplasmática, o que é indicativo de degeneração. n: núcleo do oócito; o: oócito; m: mitocôndria; re: retículo endoplasmático; cg: células da granulosa; v: vesículas. 


\section{DISCUSSÃO}

No presente trabalho, diferentes origens (SFB, SCE e SCD) em duas concentrações (10 e 20\%) de soro foram utilizadas no cultivo in vitro de FOPA caprinos por um ou sete dias. Com relação ao percentual de FOPA normais, após um dia de cultivo, apenas os tratamentos $\mathrm{MEM}^{+}$ou $\mathrm{MEM}^{+}$ com SFB, em ambas as concentrações utilizadas, foram capazes de manter percentagens semelhantes às observadas no controle. Alguns trabalhos mostraram o efeito positivo da suplementação com soro ao meio de cultivo. Telfer et al. (2000) verificaram aumento significativo na sobrevivência de folículos suínos após 20 dias de cultivo na presença de $10 \%$ de $\mathrm{SFB}$, em relação aos folículos cultivados sem soro. Cecconi et al. (1999) obtiveram rápido crescimento e alta proporção na formação de antro utilizando $10 \%$ de SFB durante o cultivo in vitro de FOPA de ovelhas. Esses resultados podem ser atribuídos a fatores de crescimento e endócrinos, presentes no soro, os quais permitem manter a viabilidade e promover o crescimento de FOPA.

Neste estudo, o cultivo in vitro na ausência ou presença de diferentes origens de soro, em ambas as concentrações testadas, aumentou significativamente o percentual de folículos ativados em relação ao controle. Além disso, quando comparado ao $\mathrm{MEM}^{+}$, após um dia de cultivo, o meio contendo $20 \%$ de SCE mostrouse mais eficaz em promover a ativação folicular. Acredita-se que a variação, bem como a concentração dos componentes séricos, de acordo com o status fisiológico da cabra, pode influenciar o desenvolvimento de FOPA caprinos. Nesse tratamento, também foi observado aumento no diâmetro folicular. No entanto, este resultado pode não ser devido ao crescimento normal do folículo, uma vez que a adição de $20 \%$ de SCE ao meio de cultivo in vitro não foi capaz de manter o percentual de folículos morfologicamente normais similar ao controle. Hulshof et al. (1995) também observaram aumento significativo do diâmetro de FOPA bovinos cultivados na presença de $17 \beta$ estradiol, substância presente em grandes quantidades no SCE. Entretanto, esse resultado foi causado pelo aumento no tamanho das células da granulosa e não devido à proliferação dessas células. No presente estudo, FOPA cultivados na presença de SCE apresentaram grande quantidade de gotas lipídicas. O acúmulo anormal no número dessas estruturas foi observado em embriões ovinos cultivados com soro (Abe et al., 2002). Mucci et al. (2006) também mostraram que a presença dessas estruturas em embriões bovinos cultivados com soro de vaca em estro parece alterar os mecanismos celulares responsáveis pelo reparo da membrana plasmática, após a criopreservação. Apesar de os folículos cultivados em $\mathrm{MEM}^{+}$ou $\mathrm{MEM}^{+}$com $10 \%$ de SFB terem apresentado alterações morfológicas reveladas pela análise ultra-estrutural, estas se localizavam principalmente no oócito, indicando sinais de atresia em estágio inicial. Os FOPA cultivados com $20 \%$ de SCE estavam mais severamente degenerados, sendo essa degeneração observada inclusive nas células da granulosa. Esses achados de degeneração podem ser devido às concentrações inadequadas de algumas substâncias-chave envolvidas na regulação do desenvolvimento folicular normal, como, por exemplo, o hormônio folículo estimulante. Recentemente, Matos et al. (2007) mostraram que a adição desse hormônio na concentração de $50 \mathrm{ng} / \mathrm{ml}$ ao meio de cultivo in vitro de FOPA caprinos é essencial para a manutenção da viabilidade e do crescimento folicular por um período de sete dias.

O nitrito é um produto resultante do metabolismo do NO durante as reações metabólicas normais, sendo possível relacionar sua concentração nas amostras aquosas com a concentração de NO produzidas (Dixit e Parvizi, 2001). Quanto ao desenvolvimento folicular, o NO tem sido considerado um potencial regulador, pois está envolvido em várias funções fisiológicas no ovário, incluindo a ovulação e a esteroidogênese (Matsumi et al., 1998a; Mitsube et al., 1999). Estudos mostraram que a óxido nítrico sintetase indutora (iNOS), uma das enzimas responsáveis pela síntese de NO, tem sido predominantemente localizada nas células da granulosa de grande parte do folículos antrais imaturos normais, enquanto as células da granulosa de folículos antrais maturos normais ou de folículos atrésicos são desprovidas dessa enzima (Matsumi et al., 1998a,b). Este foi o primeiro trabalho a relacionar concentrações de nitrito com a viabilidade de FOPA, em que se verificou correlação positiva entre a percentagem de FOPA morfologicamente normais e a produção desta substância após um e sete dias de cultivo. É 
importante ressaltar que os tratamentos que apresentaram maiores percentuais de folículos normais $\left(\mathrm{MEM}^{+}\right.$ou $\mathrm{MEM}^{+}$com $10 \%$ de SFB ou $\mathrm{SCE})$ também foram os que mostraram as maiores concentrações de nitrito. Este resultado indica que as células da granulosa desses folículos estavam normais, o que foi confirmado pela análise ultra-estrutural.

Em conclusão, a suplementação do meio de cultivo com todos os tipos (soro fetal bovino, soro de cabra em estro ou soro de cabra em diestro) e concentrações (10 ou 20\%) de soro testados neste trabalho não foi capaz de manter a viabilidade, embora tenha promovido a ativação de FOPA caprinos cultivados in vitro. Um outro achado deste trabalho foi $o$ de que as concentrações de nitrito no meio de cultivo funcionam como indicador da viabilidade das células da granulosa de FOPA caprinos cultivados in vitro.

\section{REFERÊNCIAS BIBLIOGRÁFICAS}

ABE, H.; YAMASHITA, S.; SATOH, T. et al. Accumulation of lipid droplets in bovine embryos and cryotolerance of embryos developed in different culture systems using serum-free or serum-containing media. Mol. Reprod. Dev., v.61, p.57-66, 2002.

CECCONI, S.; BARBONI, B.; COCCIA, M. et al. In vitro development of sheep preantral follicles. Biol. Reprod., v.60, p.594-601, 1999.

CHUN, S.Y.; EISENHAUER, K.M.; KUBO, M. et al. Interleukin-1 1 suppresses apoptosis in rat ovarian follicles by increasing nitric oxide production. Endocrinology, v.136, p.3120-3127, 1995.

DIMMELER, S.; HAENDELER, J.; NEHLS, M. et al. Suppression of apoptosis by nitric oxide via inhibition of interleukin-1 $\beta$-converting enzyme (ice)-like and cysteine protease protein (cpp)-32-like proteases. $J$. Exp. Med., v.185, p.601-607, 1997.

DIXIT, V.D.; PARVIZI, N. Nitric oxide and the control of reproduction. Anim. Reprod. Sci., v.65, p.116, 2001.

GREEN, L.C.; TANNENBAUM, S.R.; GOLDMAN, $P$. Nitrate synthesis in the germfree and conventional rat. Science, v.212, p.56-58, 1981.

HULSHOF, S.C.J.; FIGUEIREDO, J.R.; BECKERS, J.F. et al. Effects of fetal bovine serum, FSH and $17 \beta-$ estradiol on the culture of bovine preantral follicles. Theriogenology, v.44, p.217-226, 1995.

MATOS, M.H.T.; LIMA-VERDE, I.B.; LUQUE, M.C.A. et al. Essential role of follicle stimulating hormone in the maintenance of caprine preantral follicle viability in vitro. Zygote, v.15, p.173-182, 2007.

MAO, J.; WU, G.; SMITH, M.F. et al. Effects of culture medium, serum type, and various concentrations of follicle-stimulating hormone on porcine preantral follicular development and antrum formation in vitro. Biol. Reprod., v.67, p.1197-1203, 2002.

MATSUMI, H.; YANO, T.; KOJI, T. et al. Expression and localization of inducible nitric oxide synthase in the rat ovary: a possible involvement of nitric oxide in the follicular development. Bioch. Bioph. Res. Commun., v.243, p.67-72, 1998a.

MATSUMI, H.; KOJI, T.; YANO, T. et al. Evidence for an inverse relationship between apoptosis and inducible nitric oxide synthase expression in rat granulosa cells: a possible role of nitric oxide in ovarian follicle atresia. Endocrinology, v.45, p.745$751,1998 b$.

MITSUBE, K.; MIKUNI, M.; BRANNSTROM, M. Effects of a nitric oxide donor and nitric oxide synthase inhibitors on luteinizing hormone-induced ovulation in the ex-vivo perfused rat ovary. Hum. Reprod., v.14, p.2537-2543, 1999.

MUCCI, N.; ALLER, J.; KAISER, G.G. et al. Effect of estrous cow serum during bovine embryo culture on blastocyst development and cryotolerance after slow freezing or vitrification. Theriogenology, v.65, p.15511562,2006

SAHA, S.; SHIMIZU, M.; GESHI, M. et al. In vitro culture of bovine preantral follicles. Anim. Reprod. Sci., v.63, p.27-39, 2000.

STEEL, R.G.D.; TORRIE, J.H.; DICKEY, D. (Eds). Principles and procedures of statistics: a biometrical approach. 3.ed. New York: McGraw-Hill , 1997. $666 \mathrm{p}$.

TELFER, E.E.; BINNIE, J.P.; MCCAFFERY, F.H. et al. In vitro development of oocytes from porcine and bovine primary follicles. Mol. Cell. Endocrinol., v.163, p.117-123, 2000.

THOMAS, F.H.; LEASK, R.; SRSEN, V. et al. Effect of ascorbic acid on health and morphology of bovine preantral follicles during long-term culture. Reproduction, v.122, p.487-495, 2001.

WRIGHT, C.S.; HOVATTA, O.; MARGARA, R. et al. Effects of follicle-stimulating hormone and serum substitution on the in-vitro growth of human ovarian follicles. Hum. Reprod., v.14, p.1555-1562, 1999.

ZHOU, H.; ZHANG, Y. Regulation of in vitro growth of preantral follicles by growth factors in goats. Domest. Anim. Endocrinol., v.28, p.235-242, 2005. 